\title{
A EXPERIÊNCIA EDUCATIVA NA FORMAÇÃO INICIAL DE PROFESSORES
}

\author{
EDUCATIONAL EXPERIENCE IN INITIAL TEACHER EDUCATION
}

\author{
VIEIRA,Flávia \\ flaviav@ie.uminho.pt \\ Instituto de Educação da Universidade do Minho
}

\begin{abstract}
RESUMO No presente texto discute-se o lugar da experiência educativa na formação inicial de professores, argumentando-se a favor de uma epistemologia praxeológica direcionada à interrogação e à transformação da educação escolar. Parte-se de uma crítica ao modo como os programas de formação tendem a afastarse da sua função profissionalizante, silenciando a experiência educativa e favorecendo a hegemonia do conhecimento acadêmico, o que reforça o divórcio entre quem pensa e quem pratica a educação e impede a formação de profissionais reflexivos. Ainda a este propósito, são evidenciados problemas que afetam o estágio nesses programas e o modo como as reformas de orientação transformadora podem encontrar resistência, sinalizando a prevalência de uma cultura fragmentada e desprofissionalizada, face à qual se torna necessário contrapor a agência dos formadores no estudo e avanço da sua profissão. Finalmente, apresenta-se uma estratégia que pode favorecer uma pedagogia da experiência na formação - análise e construção de casos de ensino. Ao promover uma epistemologia praxeológica na reconfiguração do conhecimento profissional, a estratégia gera processos de aprendizagem potencialmente transformadores e emancipatórios, para além de favorecer a produção de conhecimento sobre a formação.
\end{abstract}

PALAVRAS-CHAVE: Formação Inicial. Experiência Educativa. Pedagogia da Experiência.

ABSTRACT The present text discusses the place of educational experience in initial teacher education, arguing for a praxeological epistemology aimed at interrogating and transforming school education. A critical stance is taken towards the way teacher education programmes tend to deviate from a professionalising purpose by silencing educational experience and favouring the hegemony of academic knowledge, which reinforces the divorce between those who think and those who act in education, and hampers the development of reflective professionals. Problems affecting the practicum in those programmes are pointed out, as well as the way transformative reforms may encounter resistance that signals the prevalence of a fragmented, deprofessionalised culture. This culture calls for the agency of teacher educators in the study and advancement of their profession. Finally, a strategy that can favour a pedagogy of experience in teacher education is presented - the analysis and construction of teaching cases. By fostering a praxeological epistemology in the reconfiguration of professional knowledge, the strategy generates potentially 
transformative and empowering learning processes. Furthermore, it favours the production of knowledge about teacher education.

KEYWORDS: Initial Teacher Education. Educational Experience. Pedagogy of Experience.

\section{NÃO-LUGAR DA EXPERIÊNCIA NA FORMAÇÃO INICIAL}

Neste ponto, examina-se o lugar da experiência educativa na formação inicial de professores. Evidencia-se o modo como a ausência e a presença de uma epistemologia praxeológica determinam a natureza e o impacto da formação, e defende-se uma maior agência dos formadores no estudo e reconfiguração da sua profissão. No ponto seguinte, ilustrar-se-á a visão de formação aqui defendida a partir de uma experiência profissional.

\subsection{Longe da vista, longe do coração...}

O ditado popular "Longe da vista, longe do coração" poder-se-ia aplicar ao modo como os programas de formação inicial de professores tendem a distanciar-se da experiência educativa das escolas, ignorando-a ou desvalorizando-a, embora veiculando discursos teóricos normativos e progressistas acerca do que a educação escolar deveria ser. Esse é um dos problemas mais persistentes da formação e por isso continua a exigir a nossa atenção, o que implica examinar o lugar que a experiência ocupa e pode ocupar nas práticas formativas.

Tomando uma metáfora antropológica inspirada em Marc Augé (2012), talvez possamos dizer que a experiência educativa tem ocupado uma espécie de não lugar nos programas de formação - falta-lhe uma história, uma identidade, uma dinâmica de relações sociais (op. cit., p. 52). Relega-se a prática pedagógica para um espaço curricular (o estágio) desgarrado dos restantes, onde formandos e formadores desenvolvem frequentemente ações dispersas na ausência de um projeto unificador que favoreça diálogos e entendimentos interpessoais e interinstitucionais. Como afirma ainda Augé (op. cit., p. 96), "o não-lugar é o contrário da utopia: existe e não alberga qualquer sociedade orgânica". Assim, quando a experiência educativa constitui um não-lugar, dificilmente pode comportar um potencial transformador e 
emancipatório, na medida em que não implica uma comunidade de atores na construção de práticas e ideais partilhados.

No cerne desse problema está a prevalência de uma epistemologia positivista na formação profissional, baseada numa racionalidade técnica que ignora a natureza moral e política da experiência educativa e pressupõe que a competência do professor reside, fundamentalmente, na aplicação de conhecimentos teóricos aos problemas da prática (SCHÖN, 1987). Em oposição a esta perspetiva, importa reconhecer a natureza ideológica da experiência enquanto praxis problematizadora e transformadora, assente no propósito de denunciar e superar as condições que a oprimem através da inserção crítica dos sujeitos (FREIRE, 2003, p. 38), ou seja, enquanto prática ética, reflexiva, historicamente constituída e socialmente situada, que procura dar expressão a um compromisso com propósitos educativos válidos (CARR, 2007, p. 276). Importa, pois, desenvolver uma epistemologia praxeológica de natureza construtivista na formação de professores, assente em processos de reflexão-ação incidentes na experiência educativa.

A experiência educativa é o único lugar a partir do qual se pode capturar a sua natureza única, compósita e indeterminada (SCHÖN, 1987), escrutinar o que nela se revela irracional e injusto, e traçar movimentos de libertação que são também movimentos de esperança e abertura a outros modos de pensamento, da linguagem, da sensibilidade, da ação e da vontade (LARROSA BONDÍA, 2010, p. 88). Desenvolver uma epistemologia praxeológica na formação implica que esta se constitua como um "terceiro espaço" onde confluam e se reconstruam diversos tipos de saber (ZEICHNER, 2010) e se realizem "aprendizagens de fronteira", resultantes do diálogo entre atores com diferentes trajetórias, competências e valências (WENGER, 2000). Implica, também, conceber a pedagogia escolar como uma "terceira margem do rio", superando as dicotomias que empobrecem a nossa forma de (vi)ver a educação (NÓVOA, 2011) e, portanto, como uma prática "re(ide)alista" (JIMÉNEZ RAYA; LAMB; VIEIRA, 2007), situada entre o real e o ideal e fundada na esperança como crença na possibilidade (VAN MANEN, 1990).

\subsection{Das reformas às práticas}


Centremo-nos, por um momento, no espaço curricular dos programas de formação inicial onde a experiência educativa parece ocupar um lugar central: o estágio. Aí, é impossível ignorá-la. Fica mais perto da vista. Mas ficará também mais perto do coração? Não necessariamente.

Tomemos o caso do estágio nos mestrados em ensino da Universidade do Minho, criados no âmbito da reforma instigada pelo Processo de Bolonha e em funcionamento desde 2008-2009 ${ }^{1}$. Nesses novos cursos de dois anos, onde se realiza a formação inicial dos futuros professores, o estágio foi concebido como uma unidade curricular ${ }^{2}$ com a duração normal de dois semestres $\left(2^{\circ}\right.$ ano), durante os quais os estagiários frequentam seminários de suporte à compreensão dos contextos da prática, desenham um projeto pedagógico com o apoio dos supervisores da escola e da universidade, desenvolvem esse projeto em turmas do supervisor da escola e documentam-no num portefólio reflexivo e num relatório final que defendem em provas públicas. Os princípios que regem a natureza do projeto são explicitados no regulamento interno do estágio: adequação aos contextos da prática; orientação para a compreensão e melhoria da prática; fundamentação éticoconceptual orientada para uma educação inclusiva, centrada nas aprendizagens e favorecedora do sucesso educativo; investigação ao serviço da pedagogia; potencial formativo no desenvolvimento de capacidades de reflexão, autodireção, colaboração e criatividade/ inovação do futuro professor.

Em face de modelos anteriores, o novo modelo de estágio introduz mudanças significativas no que diz respeito à articulação investigação-ensino e à valorização explícita de uma epistemologia praxeológica na construção do conhecimento profissional, visando conferir à formação uma orientação transformadora e emancipatória. Podemos dizer que se concebe o estágio como um "terceiro espaço" (ZEICHNER, 2010) de natureza multidisciplinar e teórico-prática, onde os futuros professores devem ensinar investigando e investigar ensinando, e onde a teorização da ação educativa deverá emergir do confronto de saberes disciplinares e educacionais, experienciais e teóricos, substantivos e processuais, conduzindo ao

\footnotetext{
${ }^{1}$ Em resultado do Processo de Bolonha, foram extintas as licenciaturas integradas de formação de professores, de quatro ou cinco anos. A profissionalização é agora obtida em mestrados em ensino de dois anos ( $2^{\circ}$ ciclo de formação), após uma licenciatura ( $1^{\circ}$ ciclo) de três anos em áreas disciplinares (Matemática, Biologia/ Geologia, etc.).

${ }^{2}$ Nova designação para "disciplina", adotada no âmbito do Processo de Bolonha.
} 
desenvolvimento de profissionais reflexivos e de práticas escolares de orientação democrática.

Ao nível da conceção do modelo, tudo parece ser coerente. No entanto, a experiência dos últimos quatro anos, que tenho vindo a acompanhar e a avaliar na qualidade de coordenadora do estágio nos mestrados em ensino, tem mostrado que é extremamente difícil superar uma tradição ao longo da qual se foi naturalizando uma cultura de formação aplicacionista, fragmentada e desprofissionalizada. Com efeito, à exceção de alguns projetos isolados que no passado se distanciavam de práticas dominantes (v. por ex., MOREIRA, et al., 2010; MOREIRA; VIEIRA, 2012), o estágio sempre sofreu de indefinições acerca das suas finalidades e estratégias, o que corresponde ao que a literatura nacional e internacional nos diz sobre a prática pedagógica na formação inicial de professores (v. CANÁRIO, 2002; ESTRELA, ESTEVES; RODRIGUES, 2002; FORMOSINHO, 2009; 2011; SIKES; BIRD; KENNEDY, 2010).

Mas os problemas do estágio refletem problemas mais vastos. A prevalência de uma epistemologia positivista nos programas de formação tem sido acompanhada de uma academização excessiva desses mesmos programas, radicada num paradigma de especialização monodisciplinar que se afasta de preocupações de ordem profissionalizante, desvalorizando o estatuto da formação e do formador, com implicações nas relações entre universidades e escolas (FORMOSINHO, 2009; 2011). O estágio, constituindo um campo de intervenção de natureza multidisciplinar no seio de uma cultura fortemente disciplinarizada, foi-se transformando num não lugar, uma terra de ninguém onde muitos participam, mas poucos investem de forma sistemática, e onde dificilmente se reconhecem marcas de um modo próprio de pensar e fazer a formação.

Assim, o sucesso do novo modelo de estágio exige a reconfiguração das práticas curriculares na sua globalidade, de forma a que se tornem mais coerentes com a visão de ensino e de formação que informa o desenho dos cursos:

Vivendo-se hoje numa era da informação e da comunicação, do conhecimento e da aprendizagem, na qual se jogam forças e lógicas conflituais, exige-se do professor um conjunto alargado de competências (conhecimentos, capacidades, atitudes, valores) que the permitam desempenhar um papel relevante na construção de uma escola reflexiva e na formação de cidadãos informados, críticos e atuantes. Assim, também o professor deve ser um profissional informado, crítico e atuante, capaz de 
reconstruir o seu pensamento e ação ao longo da vida. Ensinar implicará, desta perspectiva, estruturar, monitorizar e avaliar aprendizagens socialmente relevantes, no quadro do desenvolvimento integral dos indivíduos e da sua inclusão plena na escola e na sociedade.

(...) Os currículos de formação não podem, portanto, centrar-se exclusivamente na transmissão de saberes teóricos ou práticos, devendo incorporar metodologias orientadas pelos princípios da reflexividade, autodetecção, criatividade e inovação, conferindo lugar de destaque à investigação, não só como fonte de conhecimento, mas sobretudo como modo de conhecer e intervir (excerto de um dos Dossiês de criação dos mestrados em ensino).

Como se propõe em seguida, a reconfiguração das práticas curriculares implica mudanças no papel dos formadores como produtores de conhecimento sobre e para a formação, e nos modos de produção desse conhecimento.

\subsection{0 papel dos formadores: indagar a formação}

Melhorar a qualidade da formação requer uma maior articulação entre as pedagogias de formação, a investigação da formação e o desenvolvimento profissional dos formadores, numa abordagem que poderíamos designar como indagação da formação e que integra o estudo, a inovação e a disseminação de práticas, idealmente no seio de comunidades profissionais (v. SHULMAN, 2004a). Embora esta abordagem ainda represente um movimento marginal no ensino superior em Portugal, desenvolvendo-se em contracorrente face a modos de trabalho dominantes (v. VIEIRA, 2009a), pode reforçar a agência dos formadores na produção de conhecimento relevante sobre e para a formação. Trata-se, essencialmente, de desenvolver uma epistemologia praxeológica para a compreensão e o avanço da profissão.

Foi com esses pressupostos em mente que se constituiu no Instituto de Educação (IE) da Universidade do Minho, em meados de 2012, um Círculo de Estudos para os docentes dos mestrados em ensino, com a finalidade de analisar e melhorar políticas e práticas de formação inicial. Essa iniciativa foi proposta pelo Grupo de Trabalho-Inovação Pedagógica (GT-IP), na coordenação do qual participo e que foi constituído no âmbito do programa da Presidência do IE em 2010. O trabalho do GT-IP radica na ideia da indagação da pedagogia e tem como objetivos estimular a reflexão interna e promover a melhoria das práticas, apoiando as 
estruturas de gestão pedagógica nos processos de inovação e incentivando a disseminação de estudos e experiências.

Em 2010/11, com base num levantamento de áreas prioritárias de intervenção junto dos diretores de curso, o GT-IP dinamizou oficinas de reflexão e recolheu perceções dos docentes sobre a articulação curricular e pedagógica, concluindo-se que estávamos longe de poder considerar que o novo projeto de formação inicial era plenamente conhecido de todos e assumido de forma coletiva. Reconheceu-se a prevalência de uma visão fragmentada do currículo e a falta de uma cultura de diálogo e de colaboração no contexto de trabalho. O Círculo de Estudos posteriormente proposto pelo GT-IP para 2012/13, onde participam voluntariamente cerca de 25 formadores/ supervisores de diversas áreas disciplinares, visa precisamente colmatar esses problemas, promovendo sessões de reflexão coletiva e atividades de investigação da formação realizadas em sub-equipes, envolvendo a análise documental (legislação, planos de estudos, programas, relatórios de estágio), o inquérito por questionário e entrevista a diversos atores da formação (grupos focais), e a realização, análise, partilha e disseminação de experiências formativas pelos participantes ${ }^{3}$.

Ao promover uma cultura de indagação coletiva da formação, este tipo de iniciativas valoriza a experiência dos formadores na produção de conhecimento profissional, permitindo-lhes equacionar com maior clareza os fundamentos epistemológicos, os propósitos formativos e as implicações da sua ação (FLORES; VIEIRA; FERREIRA, em publicação).

\section{PEDAGOGIA DA EXPERIÊNCIA: POSSIBILIDADES DE AÇÃO}

Neste ponto, procura-se concretizar a visão de formação defendida no ponto anterior, através da apresentação e discussão de uma abordagem que designo como pedagogia da experiência e que tenho vindo a consolidar no contexto da formação pós-graduada com professores experientes, a partir da estratégia de análise e construção de casos de ensino (VIEIRA, 2009b; 2010; 2011; 2012). Começo por referir os seus pressupostos e relato depois o modo como a

\footnotetext{
${ }^{3} \mathrm{O}$ presente texto é produto das atividades deste Círculo de Estudos na dimensão de análise, partilha e disseminação de experiências formativas.
} 
operacionalizei pela primeira vez na formação didática inicial de professores, previamente ao seu estágio, mas estabelecendo com ele algumas conexões curriculares. O propósito da apresentação dessa experiência é duplo: por um lado, evidenciar que, mesmo fora do espaço curricular do estágio, é possível e desejável aproximar a formação à experiência educativa e promover uma epistemologia praxeológica; por outro lado, ilustrar o papel do formador enquanto construtor do currículo de formação e produtor de conhecimento sobre e para a formação.

\subsection{Pedagogia da experiência e o uso de casos de ensino}

Uma pedagogia da experiência implica uma epistemologia praxeológica na formação profissional, assente numa concepção do ensino e da formação como espaços de transformação e de emancipação, visando superar a divisão entre produção e aplicação do conhecimento, entre investigação e ensino, e entre universidade e escola (CONTRERAS, 2010; KINCHELOE, 2003). O conhecimento profissional é construído a partir da experiência educativa (pessoal e de outros), implicando processos de teorização e experimentação que facilitem a construção de teorias práticas localmente válidas e socialmente úteis, permitindo aos (futuros) professores compreender a complexidade das situações educativas e tomar decisões conceptual e moralmente ajustadas aos interesses de todos quantos nelas participam. Valoriza-se uma "conexão orgânica entre educação e experiência pessoal" (DEWEY, 1963, p. 25), ou seja, uma "educação da, através da e para a experiência" (op. cit., p. 29), estando a noção de experiência associada a uma conceptualização crítica do passado e do presente com vista a um futuro melhor. Por outro lado, valoriza-se o confronto de experiências e o recurso a perspetivas teóricas múltiplas na análise das situações educativas, o que requer uma pedagogia dialógica, baseada na construção negociada do currículo-em-ação, onde se promove a "liberdade intelectual" dos formandos como liberdade de observação e avaliação exercida ao serviço de finalidades com valor educativo (DEWEY, 1963, p. 61).

A análise e a construção de casos de ensino, associadas à interpretação e produção de narrativas profissionais, pode potenciar uma pedagogia da experiência. Embora a noção de "caso" e a sua operacionalização não sejam consensuais na 
literatura sobre formação de professores (v. J. SHULMAN, 1992), pressupõe-se que os casos de ensino podem instigar a indagação crítica das situações educativas que apresentam, em confronto com outras situações (semelhantes ou distintas) e com conceitos ou princípios educacionais que eles (não) ilustram. Assim, torna-se fundamental a procura de respostas à questão: "isto é um caso de quê?":

\begin{abstract}
Afirmar que uma narrativa é um caso é um ato teórico. [...] Não quero dizer que os casos são, em si mesmos, intrinsecamente teóricos. Nem quero dizer que a finalidade dos casos é ensinar teoria. O que defendo é que qualquer história que possa ser designada como um caso deverá ser um caso de alguma coisa. Terá de ser vista como um exemplar de uma classe, uma ocorrência de uma categoria mais lata.

Por esta razão, o movimento-chave no ensino com casos ocorre quando o instrutor e os estudantes exploram a questão: "isto é um caso de quê?". À medida que se debatem com esta questão, movimentam o caso em duas direções em simultâneo. Relacionam a narrativa com as experiências (pessoais) que recordam ou com casos reais escritos ou contados por outros, ligando esse caso particular a outros casos específicos. E também relacionam a narrativa com categorias da experiência, com classificações teóricas através das quais organizam o seu mundo e lhe conferem sentido. (L. SHULMAN, 2004b, p. 474, trad.) ${ }^{4}$
\end{abstract}

Os casos podem constituir uma espécie de língua franca no seio das comunidades profissionais, possibilitando a partilha de experiências e conjugando o desenvolvimento individual com a coletivização do conhecimento profissional ( $L$. SHULMAN, 2004c, p. 543-544). São particularmente adequados à construção deste tipo de conhecimento, o qual é, na sua essência, um conhecimento prático e contextualizado, pessoal, diretamente relacionado com a disciplina que se ensina, estruturado em função das tarefas de ensino e em torno de episódios de ensino, construído e reinventado em estreita relação com a experiência (CARTER, 1992, p. 110-112). Favorecem, em particular, o conhecimento pedagógico de conteúdo, o qual permite a mediação entre o saber disciplinar e os processos de construção do saber dos alunos (L. SHULMAN, 1993).

\footnotetext{
${ }^{4}$ Texto original: "To assert that a narrative is a case is to engage in an act of theory. (...) I do not mean that cases are, in themselves, inherently theoretical. Nor do I mean that the purpose of cases is to teach theory. Instead I am claiming that any story that can be called a case must be arguably a case of something. It must be seen as an exemplar of a class, an instance of a larger category.

For this reason, the key move made in teaching with cases occurs when instructor and students explore the question, 'what is this a case of?'. As they wrestle with this question, they move the case in two directions simultaneously. They connect this narrative to their remembered (personal) experiences or to vicariously experienced cases written or recounted by others, thus relating this particular case to other specific cases. They also connect this narrative to categories of experience, to theoretical classifications through which they organise and make sense of their world."
} 
A abordagem proposta implica a análise e a produção de narrativas profissionais, entendendo-se que estas constituem um processo-produto situado e único, revelador do "eu" na sua relação com o "outro" e com os contextos da prática. Essas narrativas apresentam um elevado potencial como textos de desenvolvimento profissional e de acesso à racionalidade do professor, uma racionalidade reflexiva, multidimensional e impregnada de dilemas, que supõe uma relação estreita, embora não linear, entre o que se pensa e o que se faz (v. CLANDININ, 1992; JOHNSON; GOLOMBEK, 2002; KALAJA; MENEZES; BARCELOS, 2008; MOREIRA, 2011; ZABALZA, 1994; VAN MANEN, 1990; WEBSTER; MERTOVA, 2007).

\subsection{Um exemplo: a experiência educativa como eixo de formação}

A prática de formação aqui relatada foi desenvolvida num mestrado em ensino de Inglês e Espanhol, numa unidade curricular de didática específica (Inglês) do $1^{\circ}$ semestre do $1^{\circ}$ ano do plano de estudos, previamente ao estágio do $2^{\circ}$ ano. $\mathrm{A}$ unidade curricular tem uma carga horária presencial de 75 horas ao longo do semestre, distribuída em sessões semanais de 5 horas, e pressupõe a realização de trabalho autónomo extra-aula.

Frequentaram a unidade curricular três formandos (Hu., P. e F.) e duas formandas (M. e He. $)^{5}$, com percursos académicos e profissionais distintos: Hu., P. e F., os formandos mais jovens, não tinham formação educacional nem experiência de ensino, embora um deles (P.) tivesse começado nesse ano a lecionar Inglês numa escola do $1^{\circ}$ ciclo do ensino básico; M. havia concluído há alguns anos uma licenciatura em ensino pré-Bolonha (Inglês-Alemão), tinha alguma experiência de ensino na escola pública, mas encontrava-se desempregada; He., mais velha do que os restantes colegas, ensinava Inglês há vários anos numa escola profissional, mas não tinha formação educacional.

A unidade curricular visa promover a problematização das finalidades e modos de desenvolvimento da educação linguística em contexto escolar. O seu quadro ético-conceptual assenta na articulação entre a reflexividade profissional e a promoção de uma pedagogia para a autonomia na escola. A autonomia é entendida

\footnotetext{
${ }^{5}$ Os restantes estudantes inscritos no mestrado tiveram equivalência à unidade curricular por já serem profissionalizados para o ensino de Inglês em cursos pré-Bolonha.
} 
como um interesse coletivo ao serviço de valores democráticos, e também como uma competência dos sujeitos (professores e alunos) que implica o desenvolvimento da autodeterminação, da responsabilidade social e da consciência crítica de si, do outro e dos contextos (FREIRE, 2002; JIMÉNEZ RAYA; LAMB; VIEIRA, 2007). Pressupõe-se que o professor pode ser um agente de transformação, o que exige uma postura crítica e interventiva face aos constrangimentos que se colocam a uma pedagogia de orientação democrática, através da construção de práticas re(ide)alistas, situadas entre o real e o ideal, no espaço da possibilidade (JIMÉNEZ RAYA; LAMB; VIEIRA, 2007; VIEIRA, 2010).

De forma a desenvolver uma abordagem relevante para o futuro estágio dos estudantes, o qual envolveria o desenvolvimento de um projeto pedagógico, decidi articular a análise de casos com o desenho de um projeto de pequena escala que os envolvesse na planificação e fundamentação de uma sequência didática. Expliquei que poderiam partir deste projeto para a elaboração do projeto de estágio no ano seguinte, adaptando-o e expandindo-o em função dos contextos da prática, o que de facto veio a acontecer.

A abordagem desenvolvida integrou quatro componentes principais:

- Reflexão individual e coletiva sobre teorias e experiências pessoais, a partir de um questionário inicial cujas respostas puderam ser reelaboradas no final do semestre, e também nas tarefas de formação realizadas ao longo do semestre;

- Expansão de competências (conhecimentos, capacidades, atitudes e valores) no âmbito de uma pedagogia para a autonomia, através da análise orientada de narrativas de experiências de promoção da autonomia em contexto escolar ${ }^{6}$, da expansão do conhecimento didático e do desenho de um projeto pedagógico individual;

- Reflexão sobre o processo de aprendizagem, através de um diário de bordo com quatro entradas redigidas a partir de questões orientadoras, de um

\footnotetext{
${ }^{6}$ Quando uso esta abordagem com professores experientes em cursos de pós-graduação, eles desenvolvem experiências pedagógicas que dão origem a narrativas profissionais. Com a sua autorização, tenho usado algumas dessas narrativas noutros contextos para a análise de casos, como aconteceu na experiência aqui relatada. Uso também narrativas publicadas por outros professores, nomeadamente membros do Grupo de Trabalho-Pedagogia para a Autonomia, que coordeno desde 1997, e ainda casos apresentados em Jiménez Raya e Vieira (2011), para além de outros dispersos na literatura sobre pedagogia para a autonomia na educação em línguas.
} 
questionário intermédio de balanço da experiência de formação e de uma apreciação final das aprendizagens realizadas e dos problemas sentidos (integrada no projeto);

- Envolvimento ativo na avaliação da aprendizagem, através de autoavaliação da participação na unidade curricular e da qualidade do projeto, com base em critérios discutidos no início do semestre e com implicações na classificação final.

A avaliação dos estudantes teve por base o projeto pedagógico (avaliado por eles e por mim) e a autoavaliação da participação. Para avaliar a experiência, utilizei informação recolhida ao longo das aulas (nos questionários, diário de bordo e outras tarefas de aprendizagem), redigi um diário de ensino ao longo do semestre e analisei os projetos finais apresentados.

Discuto em seguida alguns aspectos da abordagem, convocando informação de diversas fontes. Focar-me-ei, em particular, no modo como uma epistemologia praxeológica centrada na análise e construção de casos pode favorecer a consciencialização e a reconfiguração de teorias pessoais, a construção progressiva de uma visão crítica da educação e a abertura a uma pedagogia de orientação democrática. Embora nos pontos seguintes me centre em cada um desses aspetos, eles são interdependentes e foram-se desenvolvendo em simultâneo.

\subsection{Consciencialização e reconfiguração de teorias pessoais}

Nas respostas ao questionário inicial, preenchido na primeira aula, todos os formandos se manifestaram motivados para a profissão, identificando-se com um ensino da língua centrado no desenvolvimento de competências de comunicação dos alunos. Apenas a formanda já profissionalizada referia explicitamente a promoção da autonomia:

“(...) gosto de pensar que um professor deve ser algo democrático, deixar o aluno ser participativo e fomentar essa participação. (...) Defendo no ensino das línguas, e no ensino em geral, a promoção de um ensino de qualidade, um ensino que fomente uma certa autonomia do aluno e um uso das línguas em situações reais de comunicação" (M., questionário inicial). 
Logo após o preenchimento do questionário e a partilha das respostas, confrontei os formandos com a tarefa de planificarem em grupo "uma aula ideal", o que acolheram com alguma surpresa, nomeadamente os que não tinham experiência de ensino. Observei o entusiasmo com que realizaram a tarefa, discutindo hipóteses e tomando decisões. Como era de esperar, as suas escolhas eram bastante condicionadas pelas suas teorias e vivências prévias, apesar de terem toda a liberdade de "imaginar o impossível”. No meu diário, escrevi o seguinte:

\begin{abstract}
Embora o desafio da tarefa fosse imaginar uma aula de Inglês ideal e eu tenha dito aos formandos que eram livres de "imaginar o impossível", todo o processo de desenho da aula foi pautado pelas suas perceções da realidade e por preocupações inscritas no campo do "possível". As discussões em torno da gestão do tempo exemplificam bem este aspecto, denotando preocupações de eficácia que supõem um grau significativo de controlo do professor sobre o que acontece na aula. As estratégias pedagógicas foram também sendo desenhadas à luz das suas experiências, sem qualquer referência a estratégias diretamente relacionadas com a autonomia. O espaço de manobra dos alunos na gestão da aula planeada reduz-se à pesquisa sobre bandas musicais do festival de Woodstock. Há, contudo, preocupações com a motivação dos alunos, na escolha do tema e das estratégias a implementar (diário da formadora).
\end{abstract}

Em seguida, pedi que lessem em casa um texto de Tudor (2001) sobre "visões da aula" e na aula seguinte analisaram o seu plano à luz dessas visões, identificando pontos de aproximação ou afastamento. Essa tarefa representou uma introdução à estratégia de análise de casos, onde o caso em análise era o plano elaborado. Este foi também confrontado com respostas ao questionário inicial, nomeadamente à questão $O$ que é importante que os alunos aprendam na aula de línguas?, onde o enfoque recaía no uso da língua como instrumento de comunicação, o que estava globalmente em consonância com a aula imaginada.

O confronto entre a aula planeada, o texto de Tudor e as respostas ao questionário, assim como a leitura posterior de uma primeira narrativa profissional sobre a promoção da criatividade e da autorregulação (MONTEIRO et al., 2007), analisada à luz de parâmetros de uma pedagogia para a autonomia (JIMENEZ RAYA; LAMB; VIEIRA 2007), rapidamente conduziram os formandos a movimentos de consciencialização crítica das suas visões de ensino e da sua relação com experiências pessoais e experiências alternativas: 
controlado, com algumas pinceladas de uma abordagem comunicativa, afastando-se tendencialmente de uma pedagogia para a autonomia ou da aula como lugar de socialização crítica; já começaram a contactar com práticas alternativas no ensino de línguas, refletindo sobre as suas potencialidades e alguns constrangimentos, e começam a ter algumas noções do que uma pedagogia para a autonomia implica; já criaram entre si e comigo um ambiente de comunicação aberta, muito potenciado pelo trabalho em conjunto (...), mas também pela natureza das tarefas propostas, que os levam a falar de si, ou, como dizem Contreras e Peréz de Lara (2010), a partir de si (diário da formadora).

Falar a partir de si, como argumentam Contreras e Pérez de Lara (2010), favorece a explicitação da racionalidade profissional e permite o confronto com outras racionalidades, apoiando processos de mudança. Abre caminho ao diálogo verdadeiro, através do qual educador e educandos pronunciam o mundo para o transformar (FREIRE, 2003), potenciando a consciencialização do nãoconhecimento como ponto de partida para o conhecimento. Como afirma Brew (1993, p. 97), a aprendizagem experiencial implica a autodescoberta e a desaprendizagem, e assim o conhecimento implica o não-conhecimento. A consciencialização do não-saber perante ideias e práticas alternativas abre janelas ao desconhecido como espaço de possibilidade, como um quem sabe, como um talvez (LARROSA BONDÍA, 2010), o que pode causar sentimentos de desconforto e insegurança, mas também potenciar novas compreensões e a esperança numa educação melhor.

O não conhecimento radica muitas vezes na não experiência, como se verificou, por exemplo, após a leitura de uma outra narrativa onde se descrevia e discutia o uso de portefólios como estratégia de desenvolvimento da autodireção na aprendizagem (VIEIRA; MAMEDE; LIMA, 2008). Logo no início da discussão, um formando fez o seguinte comentário: "Mas afinal o que é um portefólio? Eu leio isto, mas eu não sei o que é um portefólio. Nunca fiz um nem nunca vi um!" (P.). As narrativas profissionais podem não ser compreendidas por quem não tem experiência profissional. É necessário explorá-las com os formandos, evitando que elas sejam apenas mais um instrumento ao serviço de uma educação "bancária" focada na narração e no depósito do conteúdo programático (FREIRE, 2003).

Como sublinha Freire (2003) a propósito de uma educação problematizadora, uma abordagem dialógica exige que o conteúdo, ao invés de ser "depositado" nos educandos, se organize e constitua na sua visão do mundo, na qual se encontram 
os seus "temas geradores". A análise de casos favorece essa prática, na medida em que os caminhos de análise são traçados com a participação dos formandos, a partir das suas leituras. Nesse processo, aprendem que "ler não é só caminhar sobre as palavras, e também não é voar sobre as palavras. Ler é reescrever o que estamos lendo" (FREIRE; SHOR, 1986, s/p). Trata-se de deixarmos que o nosso "eu" se embrenhe no texto do "outro", criando para ele novos sentidos e descobrindo também novos sentidos para a nossa biografia, passada e futura.

Assim, e para que os casos possam promover a consciencialização e a reconstrução de teorias pessoais, terão de ser explorados num ambiente onde todos sejam incentivados a participar e onde todas as intervenções sejam valorizadas na construção dos sentidos da experiência. Não há leituras oficiais e únicas. É na pluralidade dos olhares que se expandem os horizontes (sempre limitados e transitórios) do conhecimento de cada um. Isso implica que o formador encoraje a dúvida como método, questione e desafie os formandos sem os julgar, integre e relacione ideias aparentemente dispersas, introduza elementos novos em função do diálogo em curso, respeite diferentes perspetivas sem prescindir da sua... Em suma, terá de colocar o seu conhecimento ao serviço da produção coletiva de novo conhecimento.

\subsection{Construção progressiva de uma visão crítica da educação}

Uma epistemologia praxeológica integra a construção de uma visão crítica da educação escolar. Torna-se essencial contrariar uma visão ingénua da realidade, desvelar constrangimentos e promover a reflexão sobre estratégias que podem ser mobilizadas para superá-los.

No questionário inicialmente preenchido, e em resposta à questão Que dilemas, problemas, obstáculos... afetam o ensino (de línguas) nas escolas?, um dos formandos respondeu "não sei" e as restantes respostas apontavam os seguintes problemas: preocupação excessiva com metas, resultados e estatísticas; falta de autoconfiança e perceção de baixa autoeficácia por parte de muitos alunos; crise da autoridade dos professores e falta de apoio dos pais na legitimação dessa autoridade; falta de apoios ao professor na escola, nomeadamente ao nível dos recursos didáticos. As suas representações eram limitadas face às inúmeras forças 
históricas e estruturais que condicionam a educação escolar. Mais tarde, após terem realizado várias leituras e discutido algumas experiências no âmbito de uma pedagogia para a autonomia, numa tarefa onde lhes pedia que identificassem constrangimentos a essa pedagogia (adapt. de JIMÉNEZ RAYA; VIEIRA, 2011), as suas respostas eram já muito mais elaboradas e diversificadas, revelando uma maior consciência de fatores que condicionam a agência do professor na transformação da educação. Por exemplo, o formando que respondera "não sei" no questionário inicial referia agora um conjunto alargado de constrangimentos, centrando-se na questão da reprodução de práticas e dos seus efeitos negativos na construção de um futuro melhor:

No contexto português, os professores ainda estão muito condicionados pelo chamado "programa" e tendem a segui-lo sem qualquer mudança. É como se fosse uma regra que nunca pode ser quebrada. A tradição são as aulas expositivas com o professor a falar e os alunos a ouvir, com pouco ou nenhum espaço de discussão. (...)

Como já referi, tendemos a criar uma imagem do professor que queremos ser com base no que vemos fazer os nossos professores. Portanto, provavelmente o nosso sistema reproduz-se década após década, porque os professores ensinam do modo como foram ensinados. (...)

Os estudos são vistos como algo que dará às pessoas uma melhor vida no futuro. Infelizmente, a cultura institucional dominante não ajuda a construir essa visão, uma vez que o ministério da educação, as escolas e até os professores não querem mudar o sistema e têm mantido uma cultura datada, com medo de mudar para algo que ainda não conhecem, com medo de tornar as coisas piores ( $F$. , tarefa de reflexão).

Esta reflexão remete-nos para um dos principiais desafios dos programas de formação: criar oportunidades para que os formandos experienciem modelos transformadores, o que os ajudará a superar a tendência para reproduzir, enquanto professores, modelos transmissivos a que foram sujeitos na sua experiência escolar. Só assim poderemos evitar atitudes de ceticismo face a teorias progressistas, uma vez que elas passam a incorporar as vivências dos formandos. No seu projeto final, refletindo sobre as aprendizagens realizadas, o mesmo formando testemunha isso mesmo:

A conclusão a que cheguei no final deste projeto é que a pedagogia para a autonomia dá os seus frutos e pode ser bastante benéfica para a aprendizagem do aluno. Digo isto enquanto aluno da Unidade Curricular de Metodologia do Ensino do Inglês, uma vez que o facto de trabalhar autonomamente, e de poder partilhar o conhecimento, dúvidas, e todo o resto com os meus colegas tornou toda a aprendizagem não só mais 
homogénea como mais divertida. Além disso, ter na professora um guia que orienta para um determinado caminho para que possamos adquirir o conhecimento por nós próprios e ao nosso ritmo facilita a aprendizagem face ao que acontece ainda na maioria das unidades curriculares, em que o professor "descarrega" conhecimento e torna tudo mais complicado para o aluno, uma vez que nem sempre é perceptível a mensagem que está a tentar transmitir.

Também por isso neste projeto decidi que adotar uma pedagogia para a autonomia seria mais benéfico para os alunos (...) (F., projeto).

Dada a complexidade da educação escolar, construir uma visão crítica da mesma implica entender a pedagogia como uma prática re(ide)alista. Uma das vantagens do uso de casos é exatamente o facto de residirem no território entre a teoria e a prática, entre o ideal normativo e o real atingível (L. SHULMAN, 2004c, p. 543). A experiência educativa apresenta uma natureza híbrida que não se concilia com um pensamento dogmático.

Um dos momentos em que estas ideias foram concretizadas perante os formandos foi a vinda de uma professora a uma das aulas, narrar uma experiência desenvolvida no âmbito da sua dissertação de mestrado (TEIXEIRA, 2011), na qual adotara intencionalmente uma abordagem re(ide)alista, alternando o que apelidou "aulas normais", dirigidas a toda a turma em função do programa e do manual, com "aulas de aprendizagem autodirigida", onde os alunos trabalhavam em função de necessidades e interesses pessoais, com base em planos de trabalho por eles definidos. Nesse dia, pedi aos formandos que refletissem no seu diário de bordo sobre a relação entre a nossa aula e a seguinte citação:

Trabalhar com casos de ensino é uma forma de aprendizagem experiencial: entramos na experiência de outros e estabelecemos conexões com a nossa própria experiência, usando ambas como lentes para pensar sobre o nosso trabalho futuro. À medida que o fazemos, questionamos práticas pedagógicas, olhamo-las de vários ângulos, desvelamos as teorias pessoais que elas incorporam, confrontamos essas teorias com visões alternativas... (JIMÉNEZ RAYA e VIEIRA, 2011, p. 10, trad. ${ }^{7}$

Vejamos um testemunho das suas reflexões, que ilustra o papel dos casos na superação de um pensamento dicotómico e na promoção de posicionamentos e escolhas pessoais informadas:

\footnotetext{
${ }^{7}$ Texto original: "Working with pedagogical cases is a form of experiential learning: we enter the experience of others and make links to our own experience, using both as lenses for thinking about our future work. As we do this, we question pedagogical practices, look at them from various angles, uncover the personal theories they embody, confront those theories with alternative views..."
} 
Todos nós fomos alunos e sabemos do que gostámos e do que não gostámos. No entanto, na generalidade, a minha experiência enquanto aluno resumiu-se sempre a uma abordagem mais tradicional do ensino/aprendizagem. $\mathrm{O}$ estudo de casos permite-nos entrar em contacto com realizações concretas de teorias, ver os seus pontos fortes, assim como as suas limitações, e ao mesmo tempo compará-las com as nossas experiências, e a partir destes dois elementos estabelecer o modo como pretendemos que a nossa prática letiva se venha a desenrolar. Ou seja, faculta-nos o conhecimento que nos permite posicionar a nossa prática face às teorias.

No caso em concreto da última aula, permitiu-me ver uma concretização de uma pedagogia para a autonomia mais possível de realizar do que as anteriores, na medida em que se tratou de uma abordagem híbrida em que, de certo modo, as vantagens de um modelo tradicional e de um modelo orientado para a autonomia puderam ser conjugadas e, consequentemente, as suas desvantagens minoradas.

Assim, encaro este caso como um modelo mais exequível, ao qual um dia poderei adaptar a minha prática letiva. Além disso, este modelo permite aos alunos relativizar as metodologias de ensino mais do que uma metodologia apenas centrada na autonomia, uma vez que lhes permite ver e estar em contacto com duas formas de lecionar os conteúdos, de forma a que eles próprios possam tomar conhecimento do triângulo que se estabelece entre educador, educando e saber, o que poderá permitir aos aprendentes moldar as suas experiências de aprendizagem futuras de forma a que se adequem melhor às suas necessidades ( $\mathrm{P}$., diário de bordo).

Esse formando mostrou-se sempre atento e crítico em relação à exequibilidade de uma pedagogia para a autonomia, problematizando as propostas apresentadas no sentido de extrair lições para o seu futuro. $\mathrm{Na}$ abordagem híbrida narrada pela professora, vê a "concretização de uma pedagogia para a autonomia mais possível de realizar" por conciliar vantagens de um "modelo tradicional" e de um "modelo orientado para a autonomia". Esta perspetiva supõe a possibilidade de se conjugarem paradigmas da educação usualmente entendidos como antagónicos. Foi também este o pressuposto da professora, mas é importante sublinhar que ela não pretendia simplesmente justapor esses paradigmas como uma forma de mitigar uma pedagogia para a autonomia. Pretendia, fundamentalmente, desenvolver uma abordagem que fosse eticamente ajustada ao seu contexto profissional, recusandose a impor aos seus alunos uma forma de aprender radicalmente distinta das suas experiências anteriores e optando por negociar com eles uma pedagogia alternativa que conciliasse diferentes interesses, rumo a uma aprendizagem mais autodirigida. A sua abordagem híbrida institui-se como uma "terceira margem do rio" (NÓVOA, 2011), mas situa-se numa perspetiva democrática da educação, onde as vozes dos professores e dos alunos são determinantes na construção do currículo. É este o sentido de uma prática re(ide)alista, através da qual os professores procuram 
conciliar as exigências do sistema e as tradições escolares com as suas aspirações a uma educação mais democrática. Foi este também o sentido dos projetos desenhados pelos formandos enquanto casos de uma pedagogia para a autonomia, onde tiveram a oportunidade de imaginar práticas re(ide)alistas que foram muito para além da sua experiência anterior e da "aula ideal" que haviam planificado no início do semestre.

\subsection{Abertura a uma pedagogia de orientação democrática}

A abertura dos formandos a uma pedagogia de orientação democrática foi-se dando progressivamente ao longo do semestre, mas adquiriu especial expressão no desenho de um projeto pedagógico. Esse projeto foi elaborado individualmente com o meu apoio, a partir de um guião semelhante ao que é fornecido para o projeto de estágio, composto por um conjunto de perguntas que procuram fomentar a reflexividade profissional e aproximar a prática pedagógica da investigação-ação, promovendo a articulação entre investigação e ensino. Por exemplo:

- Que questões e intenções pedagógicas orientam o meu plano de ação? Que competências de comunicação e de aprendizagem pretendo promover nos alunos?

- Em que medida essas intenções e competências se relacionam com uma pedagogia para a autonomia e se afastam de uma visão transmissiva da educação em línguas? Que princípios pedagógicos orientam o meu projeto?

- De que forma posso monitorizar e avaliar a qualidade da minha ação? Que informação vou recolher, como, que uso Ihe vou dar e que utilidade terá?

- O que espero aprender com este projeto para a minha atividade profissional (presente ou futura)?

- Se quisesse definir a essência do meu projeto, como a definiria? É um caso de quê?

Os formandos foram construindo uma sequência didática que depois apresentaram numa narrativa com uma extensão de 10 a 12 páginas, estruturada de acordo com algumas orientações sobre as secções a contemplar e o respectivo conteúdo:

- Folha de rosto

(Título do projeto, autor/a, unidade curricular, mestrado, data) 
- O projeto e a minha visão da educação em línguas

(Resumo do projeto e da visão da educação em línguas que o orienta)

- As minhas escolhas pedagógicas: o quê e porquê

(Área de intervenção: leitura, escrita, etc.; Contexto; Intenções; Competências de comunicação e de aprendizagem a desenvolver; Atividades e materiais; Estratégias de monitorização e avaliação da ação educativa)

- O projeto é um caso de quê?

(Conceptualização geral do projeto: convicções, pressupostos, princípios, valores... que pretende representar/ ilustrar no âmbito da educação em línguas)

- O que (não) aprendi com este projeto (Aprendizagens realizadas à luz dos objetivos da unidade curricular e do curso, dificuldades/ limitações sentidas, questões/ dúvidas que o projeto coloca e que seria importante explorar/ compreender)

- Referências bibliográficas

(Leituras referidas ao longo do projeto - normas da APA)

Embora o conceito de narrativa se aplique usualmente a acontecimentos passados, poderá também aplicar-se a acontecimentos futuros, referindo-se à descrição e interpretação de uma experiência educativa imaginada, uma história desejada que se quer vir a viver e que, na verdade, já se começa a viver no processo da sua planificação. Kilpatrick (2006, p. 14/15) sublinha a noção de projeto enquanto ato intencional em que "colocamos toda a nossa alma" e que representa "a unidade típica de uma vida meritória numa sociedade democrática". Essa perspectiva foi discutida com os formandos, e embora eles não pudessem concretizar o seu projeto no momento em que o desenharam, o plano seria já um ato intencional resultante de escolhas em cujo mérito deveriam acreditar, sabendo que poderiam lá voltar no ano de estágio, como aconteceu. Quando no ano seguinte supervisionei três destes estudantes, pude verificar a facilidade com que compreenderam o tipo de projeto a realizar e o entusiasmo com que o desenharam, recontextualizando e expandindo os projetos que tinham imaginado anteriormente. A ponte entre dois espaços curriculares desfasados no tempo foi estabelecida, o que mostra o potencial de uma epistemologia praxeológica na construção de currículos 
de formação mais integrados e coerentes. Por outro lado, mesmo durante o semestre, os dois formandos que se encontravam a lecionar (H. e P.) foram experimentando e partilhando conosco práticas semelhantes às que eram discutidas em aula, revelando que a análise de casos pode inspirar a mudança.

No desenho dos projetos, as escolhas temáticas e metodológicas prenderamse com a consciência da sua complexidade e da necessidade de desenvolver abordagens distintas das tradicionais, o que revela uma postura inovadora:

Levou-me algum tempo a decidir o que fazer para este projeto e senti-me bastante tentada a tomar o caminho mais fácil e escolher uma competência com a qual me sentia mais à vontade [na experiência de ensino]. Contudo, depois de algumas horas nas aulas de Metodologia e muita reflexão, decidi abordar uma competência que, na minha opinião, é das mais difíceis de ensinar e aprender - a escrita ( $\mathrm{H}$., projeto).

Da minha experiência como aluna e, posteriormente, como professora, creio que a competência de leitura é uma das competências mais complicadas de se explorar. (...)

Eu própria dou por mim na sala de aula a seguir uma postura tradicional, de leitura em voz alta e em que cada aluno lê um parágrafo. Esta situação leva a uma rotina que muitas vezes faz com que os alunos se sintam desmotivados. Também eu, como professora, sinto que esta rotina me desmotiva, motivo pelo qual quero ir mais além e conhecer outras abordagens mais interessantes, quer para o professor, quer para os alunos (M., projeto).

Quando perguntei a professores de Inglês o que pensam da realização de um debate em que todos participem no $9^{\circ}$ ano de escolaridade, todos me responderam que tal seria impossível, devido ao nível de conhecimentos e de maturidade dos alunos. Assim, no presente trabalho pretende-se criar um plano de ação que possibilite a passagem dessa impossibilidade à realidade, procurando gradualmente criar as condições de conhecimento para que todos participem e, acima de tudo, as condições de confiança necessárias através de um foco maior no conteúdo do que na forma e através da organização dos debates em minigrupos, em que o objetivo final não é o próprio debate mas aquilo que do debate resultará ( $P$., projeto).

Ao comparar os projetos finais dos formandos com a "aula ideal" planificada em grupo no início do semestre, observa-se uma transformação notável: ao invés de um pensamento pedagógico confinado a uma visão essencialmente transmissiva do ensino, os estudantes revelavam agora um pensamento mais complexo e aberto à exploração da pedagogia como um espaço dialógico, onde a voz dos alunos se amplia à medida que o professor cria oportunidades de reflexão, negociação e autodireção na aprendizagem. 
Os formandos reconhecem que o trabalho desenvolvido mudou a sua forma de olhar a pedagogia e o seu papel enquanto professores:

\begin{abstract}
Penso que posso afirmar que até agora no mestrado, de todos os projetos que tive que fazer no âmbito das outras unidades curriculares, este projeto me parece o mais importante se tivermos em conta que o que se pretende neste mestrado é formar professores.

É, na minha visão, o mais importante até agora principalmente porque faz uma ligação entre a teoria e a prática. Eu, como aluno inexperiente, que nunca deu nem preparou aulas, senti que seria impossível fazer um projeto destes. No entanto, com todas as leituras que fizemos durante a unidade curricular e aquelas que a professora apontou como sendo importantes para o desenvolvimento da competência da oralidade [tema do projeto], fui aprendendo quais as atividades que melhor espelham uma pedagogia para autonomia e uma aproximação comunicativa ao ensino das línguas (Hu., projeto).
\end{abstract}

Este foi um projeto muito aliciante, embora também muito trabalhoso, pois faz-nos questionar imenso as nossas crenças tão enraizadas. Desde sempre, principalmente no papel de alunos, convivemos com uma abordagem da pedagogia muito tradicional. Portanto, uma das primeiras dificuldades é conseguir quebrar as amarras que nos prendem a essa perspetiva tradicional. Ao longo do semestre fomos tendo contacto com a pedagogia para autonomia, com os seus pressupostos e com alguns casos concretos da sua aplicação, em que vimos que era possível pôr esta pedagogia em prática. Verificámos que esta não era uma pedagogia utópica. No entanto, na hora de tentar pôr em prática tudo o que fomos aprendendo, verifica-se que as amarras da perspetiva tradicional ainda têm muita força. Parece-nos que não seremos capazes de imaginar nada de novo. Mas será que é isso que se pretende? Creio que o mais importante é criar em nós a perceção de que somos capazes de fazer a mudança e que essa mudança começa na nossa prática, na forma como iremos trabalhar dentro da sala de aula (M. projeto).

Considerando a experiência na sua globalidade, posso afirmar que cumpriu o objetivo de aproximar a formação à experiência educativa e, dessa forma, promover uma epistemologia praxeológica que favorece a reflexividade profissional dos estudantes e a sua abertura a uma educação mais democrática.

\title{
3 REFLEXÕES FINAIS
}

Ao longo do texto, discuti o lugar da experiência educativa na formação inicial de professores, argumentando a favor de uma epistemologia praxeológica direcionada à transformação da educação escolar. A experiência relatada, onde explorei e avaliei uma abordagem centrada na análise e construção de casos de ensino, concretiza o meu argumento e exemplifica um movimento de indagação da 
pedagogia, condição essencial a uma maior agência dos formadores na inovação das práticas formativas e na produção de conhecimento sobre e para a formação.

A condição da experiência enquanto não-lugar nos programas de formação inicial de professores subsistirá enquanto continuarmos a insistir na ideia arrogante e antidemocrática de que os professores deverão ser executores do conhecimento produzido pelos especialistas (SMYTH, 1987), supondo-se que a solução para os problemas da educação reside na acumulação e transposição desse conhecimento. A história mostra que não é assim, e a experiência relatada aponta vantagens inerentes à promoção da autonomia epistemológica dos formandos através da construção dialógica do seu conhecimento profissional, assente em processos de reflexão-ação nos quais as teorias públicas representam, sobretudo, um instrumento de interrogação e reconfiguração de teorias e práticas pessoais. Com base nos resultados obtidos, podemos dizer que uma pedagogia da experiência pode favorecer nos futuros professores a consciencialização e a reconfiguração de teorias pessoais, a construção progressiva de uma visão crítica da educação e a abertura a uma pedagogia de orientação democrática.

Se os programas de formação não conferirem um lugar de maior destaque à experiência educativa, fazendo dela um dos principais eixos de formação ao longo do currículo, dificilmente os estudantes desenvolverão uma racionalidade crítica e comprometida com a mudança. Poderão conhecer muitas teorias e métodos progressistas, mas não compreenderão verdadeiramente o seu potencial transformador, pois essas teorias e esses métodos permanecem fora de si. Não foram compreendidos a partir de si. O mesmo se passa com aqueles formadores que, embora possuidores de vasto conhecimento sobre como formar professores, não o compreendem a partir de si e, portanto, dificilmente desenvolverão uma racionalidade crítica e comprometida com a mudança nas instituições de formação em que trabalham.

Reforçar uma epistemologia praxeológica na formação profissional implicará reforçar o estatuto da própria formação nas instituições, o que passará por uma maior articulação entre as pedagogias da formação, a investigação da formação e o desenvolvimento profissional dos formadores. Julgo que a experiência relatada opera esta articulação e ilustra o modo como o formador pode indagar a sua prática, desenvolvendo uma epistemologia praxeológica como alicerce do seu 
profissionalismo. Contudo, essa forma de trabalhar tem de se desenvolver a um nível coletivo, idealmente através da constituição de comunidades de formadores, como é o caso do Círculo de Estudos referido neste texto.

Apesar dos avanços teóricos na formação de professores, continua a ser necessário refletir sobre o que vai mal nas práticas formativas, ou então nas próprias teorias, muitas vezes irrazoáveis porque desfasadas da experiência educativa nas escolas (ALARCÃO, 2001). Deste ponto de vista, o desenvolvimento de pedagogias que favoreçam uma epistemologia praxeológica na produção de conhecimento sobre o ensino e a formação poderá favorecer um diálogo profícuo entre prática e teoria, e entre professores e formadores, em defesa de uma educação mais humanista e democrática.

\section{Agradecimentos}

Deixo aqui uma palavra de reconhecimento aos formandos que comigo desenvolveram a experiência relatada no texto, pela sua colaboração e entusiasmo, e também pelas inúmeras interrogações que $(\mathrm{me})$ foram colocando, reforçando a minha convicção de que a pedagogia da formação se faz a várias vozes.

\section{FLÁVIA VIEIRA}

Doutora em Educação pela Universidade do Minho (UMINHO/Portugal). Professora Catedrática do Instituto de Educação da UMINHO. Desenvolve projetos e publica nas áreas da formação de professores, supervisão pedagógica, educação em línguas e pedagogia no ensino superior.

\section{REFERÊNCIAS}

ALARCÃO, Isabel. Novas tendências nos paradigmas de investigação em educação. In: ALARCÃO, Isabel (org.). Escola reflexiva e nova racionalidade. Porto Alegre: Artmed. Pp. 135-144, 2001.

AUGÉ, Marc. Não-lugares. Introdução a uma antropologia da sobremodernidade. 3 ed. Lisboa: Livraria Letra Livre, 2012.

BREW, Angela. Unlearning through experience. In: BOUD, David; COHEN, Robert; WALKER, David (eds.). Using experience for learning. Buckingham: The Society for Research into Higher Education \& Open University Press. Pp. 87-98, 1993. 
CANÁRIO, Rui. A prática profissional na formação de professores. In: CAMPOS, Bártolo Paiva (org.). Formação profissional de professores no ensino superior. Porto: Porto Editora. Pp. 31-45, 2002.

CARR, Wilfred. Educational research as practical science. International Journal of Research \& Method in Education, vol.30, n.3, pp. 271-286, 2007.

CARTER, Kathy. Toward a cognitive conception of classroom management: a case of teacher comprehension. In: SHULMAN, Judith (ed.). Case methods in teacher education. New York: Teachers College Press. Pp. 111-130, 1992.

CLANDININ, Jean. Narrative and story in teacher education. In: RUSSELL, Tom; MUNBY, Hugh (eds.). Teachers and teaching. From classroom to reflection. London: Routledge Falmer. Pp. 124-137, 1992.

CONTRERAS, Domingos. Pedagogias de la experiencia y la experiencia de la pedagogia. In: ; PÉREZ DE LARA, Nuria (org.). Investigar la experiencia educativa. Madrid: Edições Morata. Pp. 241-271, 2010.

; PÉREZ DE LARA, Nuria. La experiencia y la investigación educativa. In: 21-86, 2010. (org.). Investigar la experiencia educativa. Madrid: Edições Morata. Pp.

DEWEY, John. Experience and education. New York: Collier Books, 1963.

ESTRELA, Maria Teresa; ESTEVES, Manuela; RODRIGUES, Ângela. Síntese da investigação sobre formação inicial de professores em Portugal (1990-2000). Porto: Porto Editora, 2002.

FLORES, Maria Assunção; VIEIRA, Flávia; FERREIRA, Fernando llídio. Formação inicial de professores em Portugal: problemas, desafios e o lugar da prática nos mestrados em ensino pós-Bolonha. In: Borges, M. C.; Aquino, O. F. (org.). A formação inicial de professores em diferentes contextos. Políticas, práticas e perspectivas. Uberaba: EDUFU, em publicação.

FORMOSINHO, João. A academização da formação de professores. In: (coord.). Formação de professores. Aprendizagem profissional e acção docente. Porto: Porto Editora. Pp. 73-92, 2009.

- Dilemas e tensões da atuação da universidade frente à formação de profissionais de desenvolvimento humano. In: PIMENTA, Selma Garrido; ALMEIDA, Maria Isabel de (ed.). Pedagogia universitária - caminhos para a formação de professores. São Paulo: Cortez Editora. Pp. 128-155, 2011.

FREIRE, Paulo. Pedagogia da autonomia - Saberes necessários à prática educativa. 25 ed. S. Paulo: Paz e Terra, 2002.

. Pedagogia do oprimido. 35 ed. São Paulo: Paz e Terra, 2003. 
; SHOR, Ira. Medo e ousadia - O cotidiano do professor. S. Paulo: Editora Paz e Terra, 1986, Disponível em http://www.bibliotecadafloresta.ac.gov.br (s/p)

JIMÉNEZ RAYA, Manuel; LAMB, Terry; VIEIRA, Flávia. Pedagogy for autonomy in language education in Europe - towards a framework for learner and teacher development. Dublin: Authentik, 2007.

; VIEIRA, Flávia (ed.). Understanding and exploring pedagogy for autonomy in language education - a case-based approach. Dubin: Authentik, 2011.

JOHNSON, Karen; GOLOMBEK, Paula (ed.). Teachers' narrative inquiry as professional development. Cambridge: CUP, 2002.

KALAJA, Paula; MENEZES, Vera; BARCELOS, Ana Maria (ed.). Narratives of learning and teaching EFL. NY: Palgrave Macmillan, 2008.

KILPATRICK, William. 0 método de projecto. Viseu: Livraria Pretexto e Edições Pedago, 2006.

KINCHELOE, Joe. Teachers as researchers: qualitative inquiry as a path to empowerment. 2 ed. London \& New York: Routledge Falmer, 2003.

LARROSA BONDÍA, Jorge. Herido de realidad y en busca de realidad. Notas sobre los lenguajes de la experiencia. In: CONTRERAS, Domingos; PÉREZ DE LARA, Nuria (org.). Investigar la experiencia educativa. Madrid: Edições Morata. Pp. 87116, 2010.

MONTEIRO, Estela; ALVIM, Fernanda, BRANDÃO, Ana Cristina; COSTA, Lídia. TPC: da Tortura Para Crianças ao Tempo Para Criar. Narrativa profissional não publicada. Curso de Mestrado em Ciências da Educação - Área de Especialização em Supervisão Pedagógica na Educação em Línguas Estrangeiras. Braga: Universidade do Minho, 2007.

MOREIRA, Maria Alfredo (org.). Narrativas dialogadas na investigação, formação e supervisão. Mangualde: Pedago, 2011.

; PAIVA, Madalena; VIEIRA, Flávia; BARBOSA, Isabel; FERNANDES, Isabel Sandra. A investigação-acção na formação reflexiva de professores-estagiários: percursos e evidências de um projecto de supervisão. In: VIEIRA, Flávia; MOREIRA, Maria Alfredo; BARBOSA, Isabel; PAIVA, Madalena; FERNANDES, Isabel Sandra (autoras). No caleidoscópio da supervisão: imagens da formação e da pedagogia. 2 ed. Mangualde: Edições Pedago. Pp. 45-76, 2010.

; VIEIRA, Flávia. Pre-teacher education in Portugal - the transformative power of local reform. In: PARASKEVA, João M.; TORRES SANTOMÉ, Jurjo (ed.). Globalisms and power - Iberian education and curriculum policies. New York: Peter Lang. Pp. 94-106, 2012. 
NÓVOA, António. Pedagogia: a terceira margem do rio. In: Assembleia da República (ed.). Conferência - Que Currículo para o Século XXI. Lisboa, Assembleia da República: Divisão de Edições. Pp. 39-49, 2011.

SCHÖN, Donald. Educating the reflective practitioner. San Francisco: JosseyBass Publishers, 1987.

SHULMAN, Judith (ed.). Case methods in teacher education. New York: Teachers College Press, 1992.

SHULMAN, Lee. Renewing the pedagogy of teacher education: the impact of subject-specific conceptions of teaching. In: MESA, L. M.; JEREMIAS, J. M. V. (ed.). Las didácticas específicas en la formación del profesorado. Santiago de Compostela: Tórculo Artes Gráficas. Pp. 53-69, 1993.

Teaching as community property - essays on higher education. San Francisco: Jossey-Bass, 2004a.

Just in case - reflections on learning from experience. In: . The

wisdom of practice - essays on teaching, learning, and learning to teach. San Francisco: Jossey Bass. Pp. 463-482, 2004b.

Theory, practice, and the education of professionals. In: The wisdom of practice - essays on teaching, learning, and learning to teach. San Francisco: Jossey Bass. Pp. 521-544, 2004c.

SMYTH, John. A rationale for teachers' critical pedagogy: a handbook. Victoria: Deakin University, 1987.

SYKES, Gary; BIRD, Tom; KENNEDY, Mary. Teacher education: its problems and some prospects. Journal of Teacher Education, vol. 61, n.5, pp. 464-476, 2010.

TEIXEIRA, Ana Cristina. Negociação e autodireção numa pedagogia re(ide)alista - uma experiência na disciplina de Inglês. Dissertação de Mestrado: Ciências da Educação - Supervisão Pedagógica na Educação em Línguas Estrangeiras. Braga: Universidade do Minho, 2011.

TUDOR, lan. The dynamics of the language classroom. Cambridge: CUP, 2001.

VAN MANEN, Max. Researching lived experience - human science for an action sensitive pedagogy. New York: The State University of New York, 1990.

VIEIRA, Flávia. Em contra-corrente: o valor da indagação da pedagogia na universidade. Educação, Sociedade e Culturas, vol.28, pp. 107-126, 2009a.

Para uma pedagogia da experiência na formação pós-graduada de professores. Indagatio Didactica, vol.1, n.1, pp. 32-75, $2009 \mathrm{~b}$. 
Formação em supervisão: (re)produzir a pedagogia. In: MOREIRA, Maria Alfredo; BIZARRO, Rosa (org.). Supervisão pedagógica e educação em línguas. Mangualde: Edições Pedago. Pp. 151-170, 2010.

A experiência educativa como espaço de (trans)formação profissional. Linguarum Arena, n.2, pp.9-25, 2011.

- O lugar da experiência na formação de professores. In: SOARES, Sandra Regina; BORBA, Valquíria C. (ed.). Ensino e aprendizagens: análise de práticas. Salvador: EDUNEB. Pp. 25-75, 2012.

; FLORES, Maria Assunção; FERREIRA, Fernando llídio. Articulação curricular e pedagógica. Relatório interno do Grupo de Trabalho-Inovação Pedagógica. Braga: Universidade do Minho, Instituto de Educação, 2012.

; MAMEDE, Antonieta; LIMA, Clara. Staging pedagogy for autonomy: two plays. In: JIMÉNEZ RAYA, Manuel; LAMB, Terry (ed.). Pedagogy for autonomy in language education - theory, practice and teacher education. Dublin: Authentik. Pp. 106-125, 2008.

ZABALZA, Miguel. Diários de aula - contributo para o estudo dos dilemas práticos do professor. Porto: Porto Editora, 1994.

ZEICHNER, Kenneth. Repensando as conexões entre a formação na universidade e as experiências de campo na formação de professores em faculdades e universidades. Educação - Revista do Centro de Educação UFSM, vol.5, n.3, pp. 479-503, 2010. Acesso em 14 mai. $2012 \mathrm{em:}$

http://redalyc.uaemex.mx/src/inicio/ArtPdfRed.jsp?iCve=117116968009.

WEBSTER, Leonard; MERTOVA, Patricie. Using narrative inquiry as a research method - an introduction to using critical event narrative analysis in research on teaching and learning. London \& New York: Routledge, 2007.

WENGER, Etienne. Communities of practice and social learning systems. Organization, vol.7, n.2, pp. 225-46, 2000. 